\title{
Initiation, proliferation, and improvement of a micropropagation system for mass clonal production of banana through shoot-tip culture
}

\author{
Allah Jurio Khaskheli - Muharam Ali - Syad Zakir Hussain Shah - Zohra Fatima Memon - Saleem Awan • \\ Muhammad Ibrahim Khaskheli • Mohsin Ali Khaskheli • Bilqees Magsi - Zareen Qambrani • Asad Ali Khaskheli
}

Received: 22 March 2021 / Revised: 16 April 2021 / Accepted: 16 April 2021

(C) Korean Society for Plant Biotechnology

\begin{abstract}
The present study aimed to evaluate the initiation, proliferation potential, and mass clonal production ability of a micropropagation system for banana through tissue culture. A total of 60 explants were cultured on basal media supplemented with various concentrations of BAP and NAA. Banana plants regenerated on MS basal medium (control) without the addition of BAP + NAA showed a significantly $(\mathrm{P}<0.05)$ lower survival rate with no signs of shoots up to the end of the experimental period. The results further revealed that the performance in MSS-XI medium was almost $89 \%$, followed by MSS-IX and MSS-X media, both of which showed performance up to $88 \%$. In contrast, the performance in the MSS-XVI medium was less than $60 \%$, at the less duration of time and highly shoot induction detected at MSS-XIII medium. The maximum number of shoots (4.9) was observed in the medium supplemented with growth adjuster MSS-XI, followed by the MSS-XII medium (4.5). Surprisingly, the best performance was observed for the MSR-VII medium approximately 16 days after initiation, while the lowest performance was observed with MSR-XI (approximately 31 days). The maximum rooting percentage (98\%) was observed in the MSR-V to MSR-VIII media $(98 \%)$, while the minimum rooting percentage was observed in MSR-XI (approximately 45\%).
\end{abstract}

A. Jurio Khaskheli $(\bowtie) \cdot$ M. Ali $\cdot$ S. Zakir Hussain Shah $\cdot$ Z. Fatima Memon - S. Awan - M. Ali Khaskheli - B. Magsi - Z. Qambrani

Department of Biotechnology, Faculty of Crop Production, Sindh Agriculture University, Tando Jam-70060, Pakistan

e-mail: aajkhaskheli@gmail.com

M. Ibrahim Khaskheli

Department of Plant Protection, Faculty of Crop Protection,

Sindh Agriculture University, Tando Jam-70060, Pakistan

A. Ali Khaskheli

Department of Animal Nutrition, Shaheed Benazir Bhutto

University of Veterinary and Animal Sciences, Sakrand, Pakistan
Keywords Banana, Tissue culture, Hormones, Regeneration, Shoots, Roots

\section{Introduction}

Banana (Musa species) is one of the ancient fruits known to human beings. Its whole genetic information (i. e. AA, $\mathrm{AB}, \mathrm{AAB}, \mathrm{ABB}$ ) obtained from intersects between the wild diploid species of $M$. acuminata and M. balbisiana that provide A and B genomes respectively [1]. This fruit is the fourth most significant edible crop following cereals such as rice, wheat and maize in various developing states of the world, out of which, the highly productive regions where Banana is a basic source of nourishment, trade and earnings [2]. Furthermore, obtaining the yield of bananas around the worldwide was approximately 148 million tons in year of 2016 [3].

Basically, plants of banana are multiplied through traditional breeding procedures i.e. through suckers however it has various obstacles like transmit the disease, scarcity of planting material in good quality as well as quantity and diversification in yield etc. Recently these issues can be resolved through new techniques: tissue culture which provides huge multiplication of banana plantlets at very fast rate and sterilized explant (planting material) [4]. As the world population increases day by day that raising the demand of fruit and enormous potential of exporting material along with these farmers hope to cultivate in-vitro propagated banana on a massive scale that can be possible through important explants for rapid propagation and economically important commercial varieties $[5,6]$.

Consequently, in-vitro multiplication, performs to be an important system for banana fruit, that produce plantlets which free from pests such as insects, bacteria and other micro-organisms to achieve farmer's demands $[7,8,9]$. For 
these reasons several researchers and scientists worked in the lab had proposed diverse approaches for in-vitro production of banana $[10,11,12]$ where the growing substances of plants at optimum levels observed, specifically the manufactured ones that have been integrated with soma-clonal modification [13]. The most significant component influencing the efficiency of micropropagation method is the rate of propagation. It has been noticed that the multiplication rate of banana plants is depend upon genotype and variable behaviour of same banana genotypes grew in sterilized in-vitro conditions $[14,15]$. Several varieties of banana can be multiplied through the apical meristem, this information obtained from standardized and commercialized protocols [16].

The direct regenerated technique contributes twice advantages of high multiplication rates and eradication of pest as well as diseases [17]. The sterilized explant is inoculated in a vessel possessing sterile nutrient media [18]. The proliferation of bud and development of root can be induced through phyto-hormones [19]. Along with these the proper plant growth is obtained under sterilized (free from microbes) artificial controlled conditions such as light, temperature, and humidity [20]. The sub-divisions and transformation of the old culture medium to fresh medium resulting massive propagation of tissues observed. It has been reported that approximately 10,000 plantlets obtained from a single sucker within eight months were recorded [21]. Even at optimum conditions, the certain period of time production often may lead to variations either soma-clonal or epigenetic in the artificially cultured plants interesting the very fidelity of their clonal nature. Therefore, it is necessary to establish genetic uniformity of micro-propagated shoots by recent molecular techniques.

\section{Materials and Methods}

\section{Collection of Offshoot/ Suckers of Banana Plants}

Plant material like Offshoots / Suckers of Banana detached from the mother plant, surrounding the area of Mirpurkhas, Tando Alayar, Matiari, Tando Aadam and Hyderabad district, Sindh and brought to the Plant Cell and Tissue Culture Laboratory, Department of Biotechnology, Faculty of Crop Production, Sindh Agriculture University, Tandojam for present study.

Preparation of Explants materials

Offshoot/sucker of banana was dissected acropetally and the fibers, the dead plant remainders, and the extra leaves on surface of collected plant materials (explants) were removed for inoculation and cut into the pieces of $1 \sim 1.5$ $\mathrm{cm}$ elongated. The central part was kept for further processing.

\section{Surface Sterilization}

Thoroughly cleaned the branches of offshoots and removed the outer layer to show the bud tip and adjacent bud area. The exposed regions were sterilized at the surface level with $70 \%$ alcohol for 15 minutes and then soaked into $100 \%$ ( $\mathrm{NaOCl}$ ) solution encompassing 2 to 3 drops of (Tween-20) for 30 minutes (Figure 8.42). After that, exposed region was rinsed thrice with double distilled water in order to eliminate the substances of sodium hypochlorite and ethanol. Further manipulation of the explants takes placed under laminar air flow cabinet with flame apparatuses.

Preparation of direct regeneration media

The basic ingredient of MS basal medium was measured into total of eleven conical flasks $(1000 \mathrm{ml})$ separately and each of which $800 \mathrm{ml}$ of sterilized distilled water was added. The solutions were accompanied with consecutives concentrations of BAP and IAA and mixed on magnetic stirrer. The flasks were filled with sterilized distilled water up to the final volume of 1 liter and adjusted the $\mathrm{pH}$ value of 5.8 using $1 \mathrm{~N} \mathrm{HCl}$ solution. The solution was boiled until it became transparent and transferred to culture flasks (100 $\mathrm{ml})$. The flasks were plugged accurately and autoclaved at $15 \mathrm{psi}\left(121^{\circ} \mathrm{C}\right)$ for about $20 \mathrm{~min}$. and stored in the freezer till use.

\section{Conceiving of Laminar Air Flow Cabinet}

Laminar flow cabinet was initiated approximately 40 minutes before the tissue culturing. Thoroughly, swabbed the inner whole area of cabinet with $70 \%$ alcohol and then sterilized with ultraviolet (UV) for about 15 minutes. All the equipment's such as knives, scissors, scalpels, alcohol lamps and glass plates kept for complete sterilization under laminar flow cabinet.

Experimental procedure

The experiment was laid out with Randomized Complete Block Design with three different replications. The suckers were chopped off about $3 \sim 5$ inches length and wash thoroughly under running tap water for $5 \sim 7$ minutes. 
Shoot tips were prepared by trimming corm and outer leaf sheaths from the suckers. Shoot tips were then put into a beaker containing tap water, and then brought to the laboratory and wash thoroughly with sterilized distil water under laminar air flow cabinet. The banana variety basrai was used as source of explants material. Aseptically isolated shoot tips $3 \sim 4 \mathrm{~mm}$ size of explants were cultured on MS medium with $2 \sim 5 \%$ sucrose and solidified medium with $4 \mathrm{~g}$ gelrite with various concentrations of plant growth hormones

Tissue Culturing of banana

Culturing was done as method reported [23]. Explants were cultured on each of basic medium supplemented with various continuous concentrations of 2,4-D, BAP, IAA, and NAA at regenerated stages. In addition, the regenerated shoots were separated and relocated to rooting medium.

\section{Culture Maintenance}

Cultures were maintained under incubation at $28^{\circ} \mathrm{C}$ for 24 hours in dark for embryogenesis and then transfer to growth room where fluorescent light having about 3000 lux light intensity. The optimum temperature was accompanied under $25^{\circ} \mathrm{C} \pm 2$, and $16 / 8$ hours of photoperiod's cycle.

Phenotypic Analysis and observations

Observations were made at two days intervals; whereas the changes happen were measure routinely. The survival percentage, number explants regenerated, efficiency of embryogenesis, number of shoots, length of shoots, number of roots, length of roots, number of leaves, length of leaves, ion leakage, photochemical analysis, chlorophyll content, senescence of leaves and gene expression were observed.

\section{Statistical analysis}

The concluded results were exposed to analyze through ANOVA (Analysis of Variance) under linear models of statistics. Statistically Significant Differences were then examined according to Duncan's Multiple Range Test and Random Complete Block Design (RCBD). Student Edition of Statistics (Version 8.1) Analytical Software (2005) was used and further least significant difference (LSD) test was also applied for investigative the specific probability level of significance amongst the various means of combination [22].

\section{Results and Discussion}

Concentrations of nutrient media regulating growth initiation and shoot proliferation

In order to investigate the modulating efficiency of concentration affect the growth and proliferation of shoots, the different media concentration were tested and observed the finest concentration over maximum numbers of shoots initiated. The total duration of result obtained varies with the concentration of media accessory with growth adjuster as mentioned in Figure 1. Based on the inoculation of explant in those culture media where banana explant grows very well. The inoculation of media for the initiation of shoots observed after 10.6 days, whereas other media showed slight response. The finding results were also supported with the work done by [23]. Surprisingly the topmost growth observed in media (MSS- XIII) within 55 days after the inoculation of explant in an artificial media. However, the series of events takes place at the interval of seven days in each concentration of the media that used for propagation of banana plant in an aseptic condition. While in these events the lower most growth observed appeared in (MSS- XVI) which was reaches to approximately 18 days after inoculation. Furthermore, the duration of inoculation observed in Figure 1,8,9 and 10.

Survival of shoots fluctuated under different hormonal concentrations

The results regarding different concentrations of medium indicated that maximum survival $(89 \%)$ rate was obtained

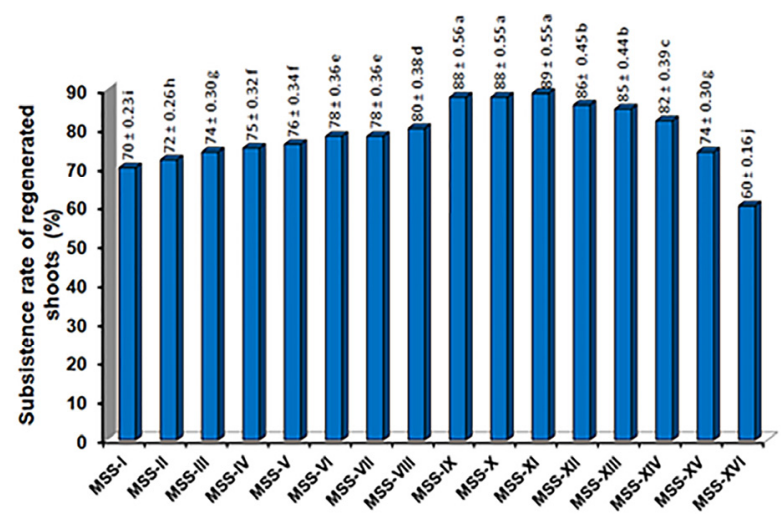

Note: Means with different letters in columns varied significantly. $\operatorname{LSD}(0.05)=$ least significant differences of means. The results are the average of four different consecutive biological replications

Fig. 1 Subsistence rate (\%) of direct regenerated shoots on MS basal medium supplemented with different concentrations of BAP and IAA 
under the concentration of MS (Basal) $+3.5 \mathrm{mg} / \mathrm{L}$ BAP $+0.5 \mathrm{mg} / \mathrm{L} \mathrm{IAA}+30 \mathrm{~g}$ Sucrose (MSS- XI) followed by MS (Basal) + $4.0 \mathrm{mg} / \mathrm{L} \mathrm{BAP}+0.5 \mathrm{mg} / \mathrm{L} \mathrm{IAA}+30 \mathrm{~g}$ Sucrose and MS (Basal) + $4.5 \mathrm{mg} / \mathrm{L} \mathrm{BAP}+0.5 \mathrm{mg} / \mathrm{L} \mathrm{IAA}+30 \mathrm{~g}$ Sucrose (MSS- IX and MSS- X) with $88 \%$ - $88 \%$ respectively. While lowest survival rate of shoots was observed $(60 \%)$ at the concentration of MS basal $+7.0 \mathrm{mg} / \mathrm{L}$ BAP $+0.5 \mathrm{mg} / \mathrm{L} \mathrm{IAA}+30 \mathrm{~g}$ Sucrose (MSS- XVI). Surprisingly, on controlled media where phyto-hormones were not used, there were no any sign of shoots observed till the end of experiment on banana plants consistently throughout the four replications.

Concentration of noticed media significantly affects the durability of shoot induction

Regeneration of banana plantlets through meristem culture offers a unique scope of developing disease free planting materials [24]. The results indicated that data regarding shoot initiate was remarkably highly significant at $5 \%$ probability level. Results further showed that the concentration of noticed media significantly effect on the duration of shoot induction of banana plants. In less period of time, outstanding performance was observed at specific quantity of media along with supplemented media. The results further revealed that different concentrations of medium indicated that early shoot was initiated after $15.3 \pm 0.16$ days of inoculations under the concentration of MS (Basal) $+5.0 \mathrm{mg} / \mathrm{L} \mathrm{BAP}+0.5 \mathrm{mg} / \mathrm{L} \mathrm{IAA}+30 \mathrm{~g}$ Sucrose (MSSXIII) followed by 16.5 and 16.4 days on the concentration of MS (Basal) $+5.5 \mathrm{mg} / \mathrm{L} \mathrm{BAP}+0.5 \mathrm{mg} / \mathrm{L} \mathrm{IAA}+30 \mathrm{~g}$ Sucrose and MS (Basal) + $4.5 \mathrm{mg} / \mathrm{L} \mathrm{BAP}+0.5 \mathrm{mg} / \mathrm{L} \mathrm{IAA}+$ 30 g Sucrose (Fig. 2), respectively. Further, the results

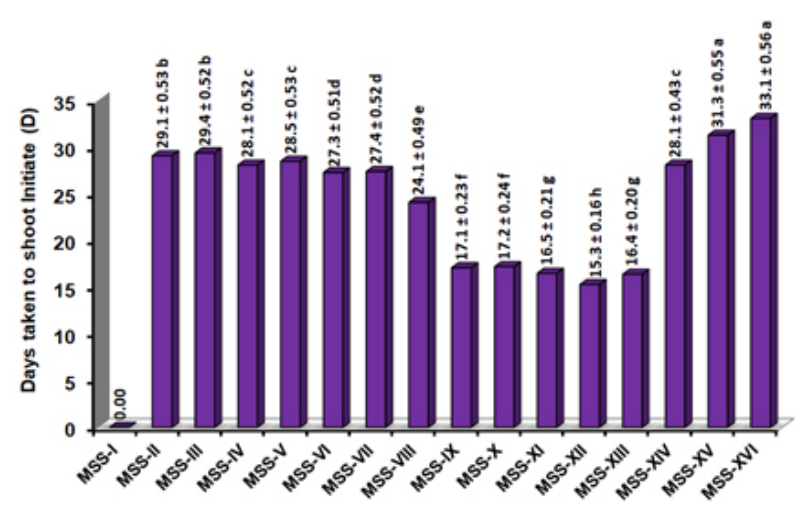

Note: Means with different letters in columns varied significantly. LSD $(0.05)=$ least significant differences of means. The results are the average of four different consecutive biological replications.

Fig. 2 Days taken to shoot initiation on MS basal medium supplemented with different concentrations of BAP and IAA indicated that the more period of time recorded $33.1 \pm 0.56$ days taken for initiation of shoots on MS (Basal) + 7.0 $\mathrm{mg} / \mathrm{L}$ BAP $+0.5 \mathrm{mg} / \mathrm{L}$ IAA $+30 \mathrm{~g}$ Sucrose (MSS- XVI) media. Furthermore, various concentrations media showed different duration of time for induction of shoots of banana plants.

Encountering the number of shoots per explants

The result for number of shoots regenerated on MS basal media supplemented with various concentrations of BAP in combination with IAA summarized in Figure 3. Results showed that on controlled media where phyto-hormones not used there was no any growth of shoots noticed till the end of experiment. The results further significantly expressed that the maximum number of shoots $(4.9 \pm 0.55)$ observed on media containing MS (Basal) $+4.5 \mathrm{mg} / \mathrm{L} \mathrm{BAP}$ $+0.5 \mathrm{mg} / \mathrm{L} \mathrm{IAA}+30 \mathrm{~g}$ Sucrose (MSS-XI) followed by $4.5 \pm 0.52$ and $4.4 \pm 0.49$ number shoots observed on media containing MS (Basal) $+5.0 \mathrm{mg} / \mathrm{L} \mathrm{BAP}+0.5 \mathrm{mg} / \mathrm{L} \mathrm{IAA}$ $+30 \mathrm{~g}$ Sucrose and MS (Basal) $+5.5 \mathrm{mg} / \mathrm{L} \mathrm{BAP}+0.5 \mathrm{mg} / \mathrm{L}$ IAA +30 g Sucrose (MSS- XII and MSS-XIII). On the other hand, the minimum number of shoots $1.2 \pm 0.19$ on the media supplemented with MS (Basal) $+0.5 \mathrm{mg} / \mathrm{L}$ BAP $+0.5 \mathrm{mg} / \mathrm{L} \mathrm{IAA}+30 \mathrm{~g}$ Sucrose (MSS-II) were observed. Besides that, different concentrations of media were found to produce various numbers of shoots of banana plants.

Length of shoots directly affected by Tissue Culture method

It was observed that the length of shoots is directly affected by tissue culture methods as well as concentration of phyto-hormones. Thus, short lengthen shoots was the

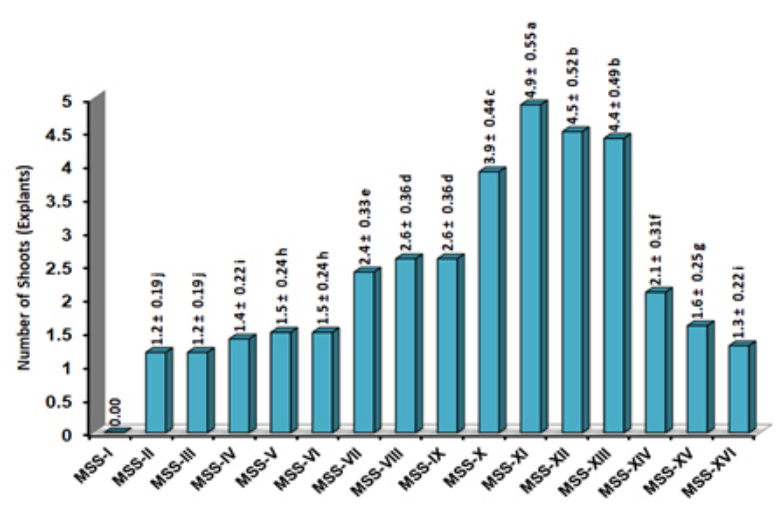

Note: Means with different letters in columns varied significantly. LSD $(0.05)=$ least significant differences of means. The results are the average of four different consecutive biological replications.

Fig. 3 The number of shoots per explant regenerated on MS basal medium supplemented with different concentrations of BAP and IAA. 


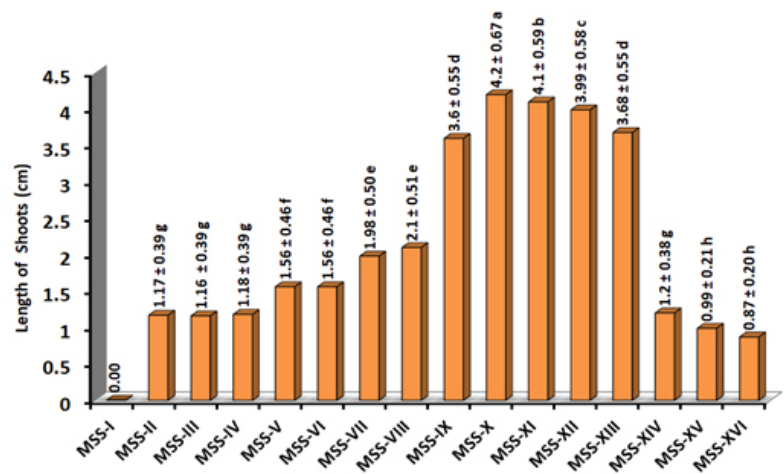

Note: Means with different letters in columns varied significantly. LSD $(0.05)=$ least significant differences of means. The results are the average of four different consecutive biological replications.

Fig. 4 The length of shoots $(\mathrm{cm})$ regenerated on MS basal medium supplemented with different concentrations of BAP and IAA

most frequent type of mutant with a frequency of up to $75 \%$ of off-types obtained from tissue culture [25]. The present results indicated that the shoot length of banana plant on in-vitro conditions remarkably higher $(4.2 \pm 0.67)$ on medium supplemented with MS (Basal) $+4.0 \mathrm{mg} / \mathrm{L}$ BAP $+0.5 \mathrm{mg} / \mathrm{L}$ IAA $+30 \mathrm{~g}$ Sucrose (MSS- X) followed by shoot length $(4.1 \pm 0.59$ and $3.99 \pm 0.58 \mathrm{~cm})$ on media containing MS (Basal) $+4.5 \mathrm{mg} / \mathrm{L} \mathrm{BAP}+0.5 \mathrm{mg} / \mathrm{L} \mathrm{IAA}+30$ g Sucrose and MS (Basal) $+5.0 \mathrm{mg} / \mathrm{L} \mathrm{BAP}+0.5 \mathrm{mg} / \mathrm{L}$ IAA $+30 \mathrm{~g}$ Sucrose (MSS- XI and MSS- XII) Figure 4. However, the minimum length of shoot $(0.87 \pm 0.20 \mathrm{~cm})$ was obtained on media containing MS (Basal) $+7.0 \mathrm{mg} / \mathrm{L}$ $\mathrm{BAP}+0.5 \mathrm{mg} / \mathrm{L}$ IAA $+30 \mathrm{~g}$ Sucrose (MSS- XVI) followed by (MSS- XV and MSS- XIII) media containing MS (Basal) $+6.5 \mathrm{mg} / \mathrm{L} \mathrm{BAP}+0.5 \mathrm{mg} / \mathrm{L} \mathrm{IAA}+30 \mathrm{~g}$ Sucrose and MS (Basal) $+0.75 \mathrm{mg} / \mathrm{L} \mathrm{BAP}+0.5 \mathrm{mg} / \mathrm{L} \mathrm{IAA}+30 \mathrm{~g}$ Sucrose $(0.99 \pm 0.21$ and $1.16 \pm 0.39 \mathrm{~cm}$ concerned the length of shoot) respectively. Along with these various concentration of media showed different shoot lengths of banana varieties in aseptic in-vitro conditions.

Days taken to initiate the roots varied with different concentrations

Results for initiation of roots depend on the period taken which normally varied with different concentration of the media along with supplemented hormones. However, the process of in-vitro rooting takes about $35 \sim 75 \%$ of the total cost of production [26]. Thus, optimization of nutrient media composition for rooting is very difficult task. In our present study we had successfully optimized this method and successfully regenerated the roots of seedlings. Surprisingly, the best performance was observed significantly

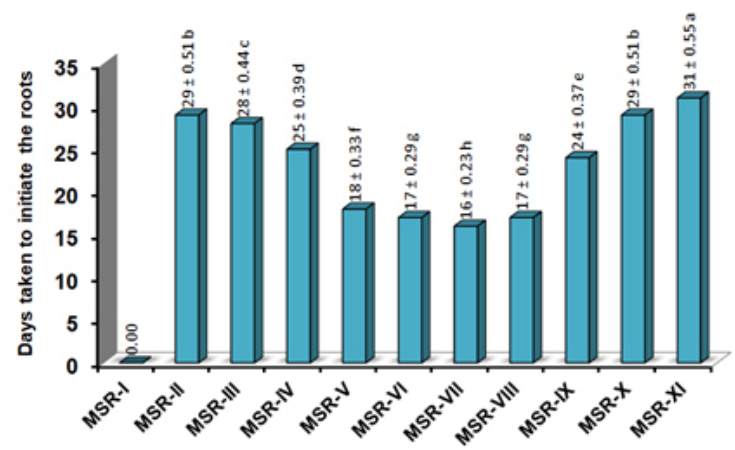

Note: Means with different letters in columns varied significantly. $\operatorname{LSD}(0.05)=$ least significant differences of means. The results are the average of four different consecutive biological replications.

Fig. 5 Days taken to initiate the roots regenerated on MS basal medium supplemented with different concentrations of NAA

$(\mathrm{P}<0.05)$ on $1 / 2 \mathrm{MS}$ (Basal) $+4.0 \mathrm{mg} / \mathrm{L} \mathrm{NAA}+30 \mathrm{~g}$ Sucrose (MSR- VII) Figure 5, where approximately 16 days were taken for initiation of roots. While the lowest performance observed on media containing 1/2MS (Basal) $+6.5 \mathrm{mg} / \mathrm{L}$ NAA +30 g Sucrose (MSR- XI) which taken about 31 days for root initiation.

Regeneration efficiency of rooted seedling positively influenced on survival

In order to investigate the rate of rooted seedlings, it has been clearly declared that significant effect of different combinations of media associated with hormones directly influenced on the survival period of rooted seedlings. The results showed that the maximum rate of survival $(98 \%$ more or less) of rooted seedlings was observed significantly $(\mathrm{P}<0.05)$ on four different consecutive concentrations of $1 / 2 \mathrm{MS}$ (Basal) $+2.0 \mathrm{mg} / \mathrm{L}$ NAA $+30 \mathrm{~g}$ Sucrose to $1 / 2 \mathrm{MS}$ (Basal) $+5.0 \mathrm{mg} / \mathrm{L}$ NAA $+30 \mathrm{~g}$ Sucrose (MSR-V to MSRVIII) followed by (95\%) of survival rate of rooted seedlings on media containing $1 / 2 \mathrm{MS}$ (Basal) $+1.0 \mathrm{mg} / \mathrm{L} \mathrm{NAA}+$ $30 \mathrm{~g}$ Sucrose and $1 / 2 \mathrm{MS}$ (Basal) $+6.0 \mathrm{mg} / \mathrm{L} \mathrm{NAA}+30 \mathrm{~g}$ Sucrose (MSR-IV and MSR-IX). Besides that, the antagonistic minimum span of life (55\%) was noticed significantly $(\mathrm{P}<0.05)$ on media containing $1 / 2 \mathrm{MS}$ (Basal) $+6.5 \mathrm{mg} / \mathrm{L}$ NAA +30 g Sucrose (MSR- XI) of the rooted seedlings (Figs. 6 and 7).

\section{Conclusions}

In present study, we have emphasized the optimized methods and indicated that shoot induction as well as root induction 


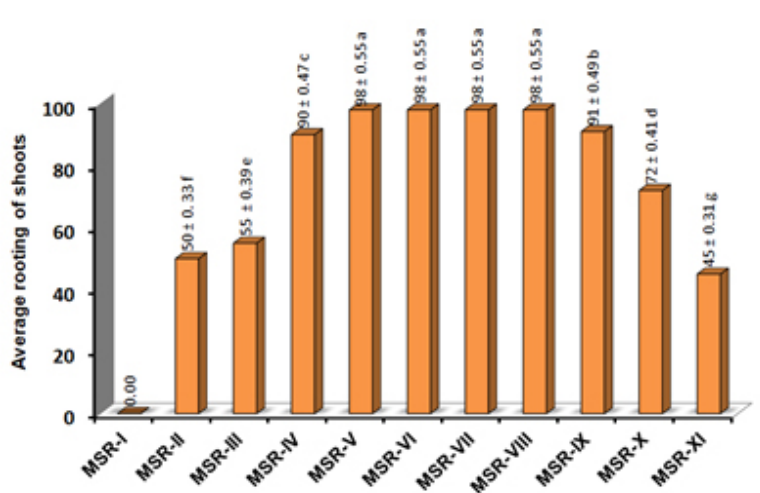

Note: Means with different letters in columns varied significantly. $\operatorname{LSD}(0.05)=$ least significant differences of means. The results are the average of four different consecutive biological replications.

Fig. 6 Average rooting of shoots regenerated on MS basal medium supplemented with different concentrations of NAA

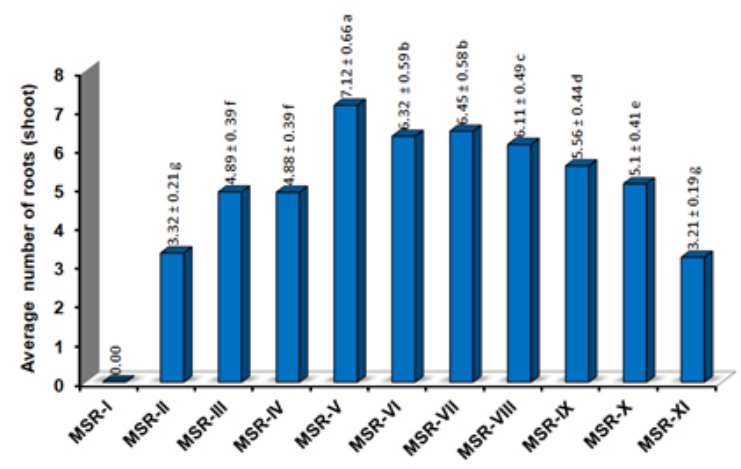

Note: Means with different letters in columns varied significantly. $\operatorname{LSD}(0.05)=$ least significant differences of means. The results are the average of four different consecutive biological replications.

Fig. 7 Average rooting per shoot regenerated on MS basal medium supplemented with different concentrations of NAA

frequency were noticeably regulated significantly $(\mathrm{P}<0.05)$ when the correct concentration of hormones used under laboratory conditions. Besides direct shoot induction, various concentrations were applied for the in vitro propagation of Banana. Generally, based on our observations, different basal medium produced calli in different morphology, thus the optimum basal medium for direct regeneration was moderately modified. For both direct and indirect regeneration, use of cytokinins alone or in combination with auxins at different concentrations for shoot induction failed to generate positive results. Additionally, for direct regeneration, BAP in combination with IAA was more effective.

\section{Conflict of Interest Disclosures}

All Authors have read the manuscript and declared that they have no any conflict of interest.

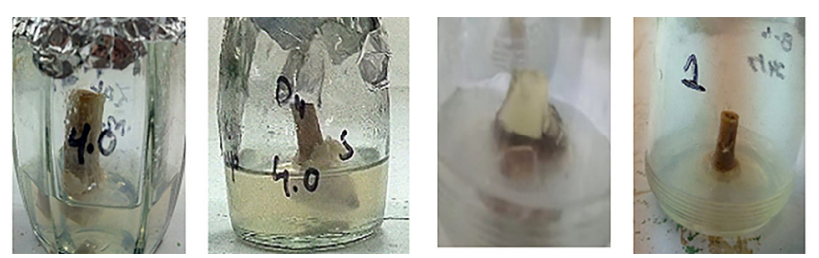

Note: The results show the outcomes of four different replications in the absence of growth hormones, and no sign of growth was noticed till the end of the experiment.

Fig. 8 Explants inoculated for direct-shoot regeneration of banana on MS (basal) + $0.0 \mathrm{mg} / \mathrm{L} \mathrm{BAP}+0.0 \mathrm{mg} / \mathrm{L} \mathrm{IAA}+30 \mathrm{~g}$ of Sucrose
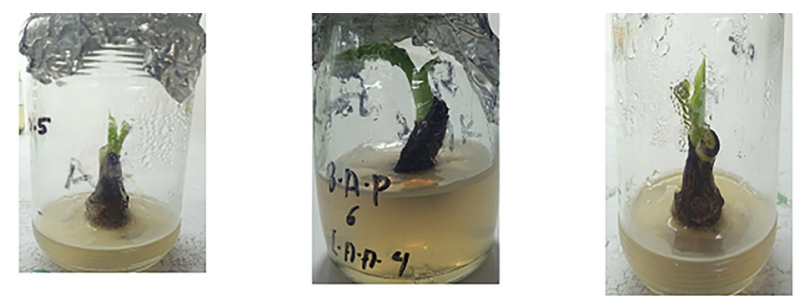

Note: The results show the outcomes of four different replications, and early response of shoot initiation and regeneration was observed.

Fig. 9 Early direct-shoot regeneration of banana observed on MS (basal) medium supplemented with various concentrations of BAP and IAA

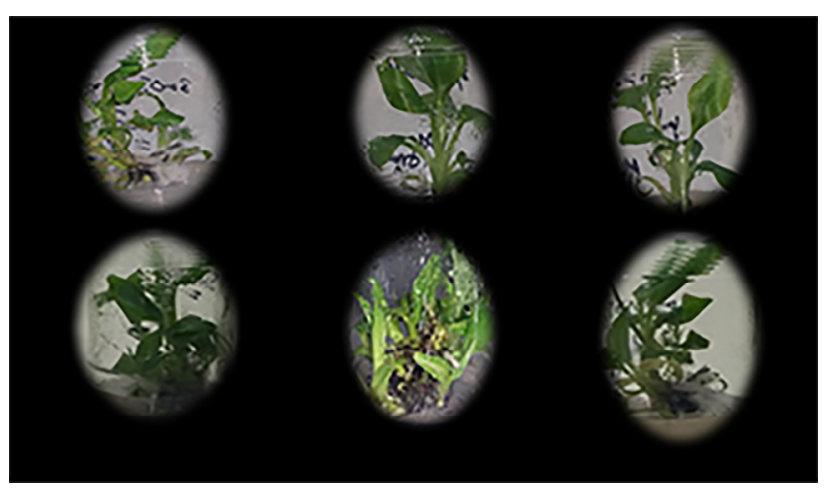

Fig. 10 Mass clonal production of banana regenerated on MS (basal) medium supplemented with various concentrations of BAP and IAA

\section{Authors' Contributions}

AJK, MA and MIK designed the experiments, SKHS, SA, ZFM,MAK and BM carried out the experiments as a masters student. AJK, MA and MIK supervised the work, AAK, ZQ and MAK revise the manuscript and analysed the data. All authors contributed to the study. All authors read and approved the final manuscript.

\section{Acknowledgement}

Authors very grateful and would like to thank School of 
Life Sciences, Lanzhou University, Gansu Province, P.R. China for provided me an opportunity for conducting Post doctorate program. And also would like to thank Department of Biotechnology, Sindh Agriculture University, Tandojam for hosted me the employment opportunity and gave me background. The present work was supported by the Higher Education Commission of Pakistan, Funded Start-up Research Grant Program [grant No. 4821].

\section{References}

Aish M, Iqbal H, Naqvi S, Hamid R (2004) Banana plantlet production through tissue culture. Pak J Bot 36:617-620. [1]

Ali A, Sajid A, Naveed NH, Majid A, Saleem A, Khan UA et al. (2011) Initiation, Proliferation and Development of MicroPropagation System for Mass Scale Production of Banana through Meristem Culture. African Journal of Biotechnology 10:15731-15738. [2]

FAO Stat. FAO Stat accessed vide http://www.fao.org/faostat/ en/\#data/QC on 12/8/2018. [3]

Heslop-Harrison J, Schwarzacher T. Domestication (2007) genomics and the future for banana. Ann Bot 100:1073-1084. [4]

Israeli Y Y, Lahav E, Reuveni O (1995) In vitro culture of bananas. Fruits 43:219-223. [5]

Krikorian AA, Cronauer SS (1984) Aseptic culture techniques for banana and plantain improvement. Econom Bot 38:322-331. [6]

Ma SS, Shii CI (1972) In vitro formation of adventitious buds in banana shoot apex following decapitation. J Chinese Soci Hort Sci 18:135-142. [7]

Madhulatha P, Anbalagan M, Jayachandran S, Sakthivel N (2004) Influence of Liquid Pulse Treatment with Growth Regulators on in Vitro Propagation of Banana (Musa spp. AAA). Plant Cell Tissue and Organ Culture 76:189-192. 10. [8]

Madhulatha P, Anbalagan M, Jayachandran S, Sakthivel N (2004) Influence of liquid pulse treatment with growth regulators on in vitro propagation of banana (Musa spp. AAA), Plant Cell, Tissue, Organ Cult, 76:189-191. [9]

Martin KP, Pachathundikandi SK, Zhang CL Madassery J (2006) RAPD analysis of a variant of banana (Musa sp.) cv. Grande naine and its propagation via shoot tip culture. In Vitro Cellular and Development Biology - Plant 42:188-192. [10]

Mendes BMJ, Mendes FJ, Neto AT, Demetrio CGB, Puske OR (1996) Efficacy of banana plantlet production by micropropagation. Pesqui Agropecu Bras 31:863-867. [11]

Ngomuo M, Mneney E, Ndakidemi PA (2014) The in Vitro Propagation Techniques for Producing Banana Using Shoot Tip Cultures. American Journal of Plant Sciences 5:1614-1622. [12] Ortiz R, Swennen R (2014) Crossbreeding to biotechnology- facilitated improvement of banana and plantain, Biotec Advances 32:158-169. [13]

Pillay M, Cullis CA, Talengera D, Tripathi L (2011) Propagation methods in Musa, In: Pillay M.,Tenkouano A. (Eds.), Banana breeding: Progress and Challenges, New York, CRC Publishers pp 312. [14]

Ray T, Dutta I, Saha P, Das S, Roy SC (2006) Genetic stability of three economically important micropropagated banana (Musa spp.) cultivars of lower IndoGangetic plains, as assessed by RAPD and ISSR markers. Plant Cell, Tiss Org 85:11-21. [15]

Robooni T, David T (2018) Improved Propagation Techniques to Enhance the Productivity of Banana (Musa spp.) Open Agriculture 3:138-145. [16]

Rout GR, Samantaray S, Das P O(2000) Biotechnology of the Banana: A Review of Recent Progress. Plant Biol 2:512-524. [17]

Roux N, Dolezel J, Swennen R Zapata-Arias FJ (2001) Effectiveness of three micropropagation techniques to dissociate cytochimeras in Musa spp. Plant Cell, Tiss Org Cult 66: 189-197. [18]

Saraswathi MS, Uma S, Kannan G, Selvasumathi M, Mustaffa MM, Backiyarani S (2006) Cost effective tissue culture media for large-scale propagation of three commercial banana (Musa spp.) varieties. The J Hort Sci Biotec 91:23-29. [19]

Saraswathi MS, Uma S, Kannan G, Selvasumathi M, Mustaffa MM, Backiyarani S (2016) Cost effective tissue culture media for large-scale propagation of three commercial banana (Musa spp.) varieties. The J Hort Sci Biotec 91:23-29. [20]

Singh TD, Singh CH, Nongalleima K, Moirangthem S, Devi HS (2013) Analysis of growth, yield potential and horticultural performance of conventional vs. micropropagated plants of Curcuma longa var. Lakadong, Afr J Biotech 12:1604-1608. [21]

Stover NW, Simmonds RH (1987) Bananas, Longman, Essex, England pp 123. [22]

Strosse H, Schoofs H, Panis B, Andre E, Reyniers K, Swennen R (2006) Development of embryogenic cell suspensions from shoot meristematic tissue in bananas and plantains (Musa spp.). Plant Sci 170:104-112. [23]

Venkatachalam L, Sreedhar R, Venkataramareddy, Bhagyalakshmi $\mathrm{N}$ (2007) Molecular analysis of genetic stability in long-term micropropagated shoots of banana using RAPD and ISSR markers. Electronic Journal of Biotechnology, ISSN: 0717-3458, Vol.10 No.1. [24]

Thimmaraju L, Sreedhar RV, Bhagyalakshmi N (2006) Direct shoot and cormlet regeneration from leaf explants of silk banana (AAB). In Vitro Cell Dev Biol Plant 42:262-269. [25]

Vuylsteke DR (1998) Shoot-tip culture for the propagation, conservation and distribution of Musa germplasm. IITA, Ibadan, Nigeria pp 82. [26] 